\title{
Harmonics analysis of 130-year hourly air temperature in Hong Kong: detecting urban warming from the perspective of annual and daily cycles
}

Article

Accepted Version

Wang, K., Li, Y., Luo, Z., Yin, S. and Chan, P. W. (2018) Harmonics analysis of 130-year hourly air temperature in Hong Kong: detecting urban warming from the perspective of annual and daily cycles. Climate Dynamics, 51 (1-2). pp. 613-625. ISSN 0930-7575 doi: https://doi.org/10.1007/s00382-0173944-y Available at https://centaur.reading.ac.uk/72896/

It is advisable to refer to the publisher's version if you intend to cite from the work. See Guidance on citing.

To link to this article DOI: http://dx.doi.org/10.1007/s00382-017-3944-y

Publisher: Springer

All outputs in CentAUR are protected by Intellectual Property Rights law, including copyright law. Copyright and IPR is retained by the creators or other copyright holders. Terms and conditions for use of this material are defined in the End User Agreement. 


\section{CentAUR}

Central Archive at the University of Reading

Reading's research outputs online 


\section{Harmonics analysis of 130-year hourly air temperature in Hong Kong: 2 detecting urban warming from the perspective of annual and daily cycles}

3 Kai Wang ${ }^{1}$, Yuguo Li $^{1^{*}}$, Zhiwei Luo ${ }^{2}$, Shi Yin ${ }^{1}$, Pak Wai Chan ${ }^{3}$

41 Department of Mechanical Engineering, the University of Hong Kong, Pokfulam, Hong Kong, 5 China

62 School of the Built Environment, University of Reading, Reading, United Kingdom

73 Hong Kong Observatory, Hong Kong, China

8 * Corresponding author, E-mail: liyg@hku.hk. Tel: +852-39172625

\section{Abstract}

The century-long search for the precise mechanisms responsible for urban heat islands continues, while urban warming worsens in many megacities. Most studies have focused on mean temperature, daily and annual temperature ranges and urban heat island intensity. We hypothesize

13 that an analysis of the changes in the characteristics of the complete daily and annual temperature 14 cycles, including not only the mean temperature and temperature ranges (amplitudes) but also the 15 maximum and minimum temperatures and the phases, can provide more information on urban 16 warming phenomena. Through a detailed analysis of long-term observations in Hong Kong, we 17 found that the difference in the daily cycle between urban and rural stations is very distinct, whereas the annual cycles are much more similar, suggesting that the urban environment has a greater effect on the daily cycle than on the annual cycle. The daily phase has shifted a total of 1.77 hours later over the last 130 years ( 1.36 hours per century) in the urban area of Hong Kong according to the Hong Kong Observatory (HKO) data. The annual phase change at HKO reflects the globally observed phenomenon that the annual phase advances or seasons onset earlier.

\section{Keywords}


Ongoing urban warming has been well documented in many studies. Urban areas are widely recognized as being much warmer than their surrounding rural areas, which is known as the urban heat island (Oke 1987). The diurnal temperature range (DTR) is smaller in urban than in rural areas due to the higher daily minimum temperature (Gallo et al. 1996). In decadal time scales, urban areas experience a greater increasing trend in daily mean temperature and a larger decreasing trend in DTR compared with rural areas or the global average (Easterling et al. 1997; Jones et al. 1990; Wang et al. 2012). Therefore, the larger magnitude changes in the mean temperature and DTR are considered to be the major indicators of urban climate change and have thus been intensively studied.

Understanding the mechanisms that cause the various phenomena involved in urban warming is critical to identifying the anthropogenic effect and natural variation in climate change. Urban areas have larger areas of impervious land, higher emission of greenhouse gases and more anthropogenic heat and air pollution than rural areas, which all contribute to the phenomena of urban warming (Arnfield 2003; Cao et al. 2016; Duren and Miller 2012; McCarthy et al. 2010; Oke 1987). However, the exact mechanisms and the relative contributions of different factors of the urban environment to urban climate dynamics are still relatively unknown. Several studies of temperature cycles suggest that there are indeed other climate variables that change independently from the mean temperature during climate change (Qian and Zhang 2015; Stine et al. 2009; Vinnikov et al. 2002; Wang and Dillon 2014). Analyzing the changes in temperature cycles may provide more information regarding the phenomena of urban warming.

Hong Kong has a monsoon-influenced humid subtropical climate. The weather is hot and humid most days of the year, particularly in summer. Less than $25 \%$ of the territory's land mass is developed, and Hong Kong is one of the most densely populated cities in the world. The city of Hong Kong has the highest population density and largest volume of buildings. Hong Kong's climate is becoming increasingly warm due to urbanization and climate change (Chan et al. 2012; Li et al. 2015; Siu and Hart 2013), and it is thus considered a good laboratory for urban climate studies. The meteorological station at the headquarters of the Hong Kong Observatory (HKO) began taking hourly observations in the 1880s. The hourly data collected over nearly 130 years 
provide us with the opportunity to conduct a comprehensive and detailed study of the annual and daily cycles in this highly urbanized city. We hope to determine the extent of the urban effect on different temperature cycles and provide more information on how the urban environment affects the climate.

\section{Data and methods}

2.1 Hong Kong Observatory hourly air temperature data

The hourly meteorological data obtained at four stations in Hong Kong were provided by HKO. The longest observation comes from the HKO station itself, which is located in the city center. Dating back to 1884 , the station has been operating for over 130 years, covering the entire period of Hong Kong's growth until it became one of the densest cities in the world. Following a previous study (Siu and Hart, 2013) and the availability of data, another urban station, King's Park (KP), and two rural stations, Ta Ku Ling (TKL) and Tsak Yue Wu (TYW), were also selected. The locations and the satellite images of the surrounding area from Google Earth of the four stations are shown in Fig. 1a. HKO $\left(22^{\circ} 18^{\prime} 07^{\prime \prime} \mathrm{N}, 114^{\circ} 10^{\prime} 27^{\prime \prime} \mathrm{E}, 32 \mathrm{~m}\right.$ above sea level) is located in a compact high-rise area, and $80 \%$ of the area around the station is built up. The development of urbanization in this area, as shown from Figure $1 \mathrm{~b}$ to Figure 1c, provides us with the opportunity to conduct a comprehensive and detailed study of the annual and daily cycles in this highly urbanized city. KP $\left(22^{\circ} 18^{\prime} 43^{\prime \prime} \mathrm{N}, 114^{\circ} 10^{\prime} 22^{\prime \prime} \mathrm{E}, 65 \mathrm{~m}\right.$ above sea level) is located $1 \mathrm{~km}$ north of $\mathrm{HKO}$, in a dispersed midrise area, and the surrounding area is $47.4 \%$ built up. TKL $\left(22^{\circ} 31^{\prime} 43^{\prime \prime} \mathrm{N}\right.$, $114^{\circ} 09^{\prime} 24^{\prime \prime} \mathrm{E}, 15 \mathrm{~m}$ above sea level) is located around $25 \mathrm{~km}$ north of HKO, a dispersed low-rise area with the surrounding area $18.1 \%$ built up, and TYW $\left(22^{\circ} 24^{\prime} 11^{\prime \prime} \mathrm{N}, 114^{\circ} 19^{\prime} 24^{\prime \prime} \mathrm{E}, 5 \mathrm{~m}\right.$ above sea level) is a Forest area, around $20 \mathrm{~km}$ northeast of $\mathrm{HKO}$, with only a $2.7 \%$ built surface around it (Siu and Hart, 2013). Hourly data used in this study date back to 1993, 1989 and 2000 at the KP, TKL and TYW stations, respectively. Note that the HKO data from 1940 to 1946 are not available due to the Second World War. Although there have been changes in the instruments and observations in $\mathrm{HKO}$, the homogeneity test conducted by a previous study showed that the impact 


\subsection{Fourier Transform}

We used the Fast Fourier Transform method to convert temperature variation into a set of harmonics. Meteorological temperature data usually form a discrete sequence of $N$ points in time, called a time series. For example, $N=24 \times 365$ for hourly data over an entire year. The infinite sum can be described by a finite sum, $M=N / 2$ harmonics (assuming that $N$ is even), i.e., the discrete Fourier transform. Periodic $N$-point air temperature variation can be transformed into the sum of harmonics with different frequencies, as follows:

$$
T(t)=\bar{T}+\sum_{j=1}^{M} \Delta \widetilde{T}_{j} \cos \left(j \omega t-\Phi_{j}\right)
$$

$\bar{T}$ is the mean temperature, $\Delta \widetilde{T}_{j}$ is the amplitude and $\Phi_{j}$ is the phase, and $\omega=2 \pi / P$ is the fundamental angular frequency, with the period $P$ for the annual cycle.

We focused on the four main harmonics representing the fundamental periodic variation extracted from the complex observed temperature profiles: annual, semi-annual, daily and semidaily harmonics. The importance of these four harmonics is evident from an example drawn from the observation data obtained at KP in 2000. Fig. 2a shows the amplitude spectrum. The strong signal for the first annual and daily harmonics reflects the primary forcing mechanism, solar radiation. The semi-daily cycle is mainly imposed by the abrupt night-time zeroing of solar radiation in addition to the heat storage of the soil and atmosphere.

The observations for an entire year can thus be treated as four periodic variations and other random variations (Fig. 2b), as follows.

$$
\begin{gathered}
T(t)=\bar{T}+\Delta \tilde{T}_{a 1} \cos \left(\frac{2 \pi}{\text { Year }} t-\Phi_{a 1}\right)+\Delta \tilde{T}_{a 2} \cos \left(\frac{2 \pi}{(\text { Year } / 2)} t-\Phi_{a 2}\right)+\Delta \tilde{T}_{d 1} \cos \left(\frac{2 \pi}{\text { Day }} t-\right. \\
\left.\Phi_{d 1}\right)+\Delta \widetilde{T}_{d 2} \cos \left(\frac{2 \pi}{(\text { Day } / 2)} t-\Phi_{d 2}\right)+\operatorname{random}(t) ; \quad(2)
\end{gathered}
$$

The major parameters are the mean temperature $\bar{T}$, amplitude $\Delta \tilde{T}_{a i}$ and phase $\Phi_{a i}$ of the annual harmonic (12-month harmonic, $i=1)$, semi-annual harmonic (6-month harmonic, $i=2)$, amplitude $\Delta \tilde{T}_{d i}$ and phase $\Phi_{d i}$ daily harmonic (24-hour harmonic, $\left.i=1\right)$ and the semi-daily cycle (12-hour harmonic, $i=2$ ). To gain a better understanding of the phase, we use the peak/bottom 
temperature occurring time, defined as the phase time in analogy with the phase angle alone, to describe the phase of each harmonic. For annual and daily harmonics, as the peak point is closer to the annual/daily maximum temperature occurring time, the phase time is calculated as the peak temperature occurring time, $\Phi_{a 1} /\left(\frac{2 \pi}{\text { Year }}\right)$ and $\Phi_{d 1} /\left(\frac{2 \pi}{D a y}\right)$. For semi-annual and semi-daily

110 harmonics, as the bottom point is closer to the annual/daily minimum temperature occurring time,

111 the phase time is calculated as the first bottom temperature occurring time, $\left(\Phi_{a 2}+\frac{\pi}{2}\right) /\left(\frac{2 \pi}{Y e a r / 2}\right)$ 112 and $\left(\Phi_{d 2}+\frac{\pi}{2}\right) /\left(\frac{2 \pi}{D a y / 2}\right)$.

The two major harmonics with mean temperature can represent most of the annual and daily variations, as shown in Fig. $2 \mathrm{c}$ and Fig. 2d. The root-mean-square error between twoharmonic synthesized and the observed data are 0.5518 and 0.0715 for the annual cycle and daily cycle, respectively. Thus, we obtain the two-harmonic synthesized annual cycle $T_{a}(t)$ and two-

117 harmonic synthesized daily cycle $T_{d}(t)$ of each year as follows:

$T_{a}(t)=\bar{T}+\Delta \tilde{T}_{a 1} \cos \left(\frac{2 \pi}{\text { Year }} t-\Phi_{a 1}\right)+\Delta \tilde{T}_{a 2} \cos \left(\frac{2 \pi}{(\text { Year } / 2)} t-\Phi_{a 2}\right)$,

$T_{d}(t)=\bar{T}+\Delta \tilde{T}_{d 1} \cos \left(\frac{2 \pi}{D a y} t-\Phi_{d 1}\right)+\Delta \tilde{T}_{d 2} \cos \left(\frac{2 \pi}{(D a y / 2)} t-\Phi_{d 2}\right)$

120 According to these two equations, we can then calculate the annual and daily maximum $/ \mathrm{minimum}$ 121 temperature ( $\left.T x \_a, T n \_a, T x \_d, T n \_d\right)$ and their differences in annual temperature range (ATR) 122 and DTR, respectively. The $T x$ and $T n$ are found to be closely related to the amplitudes and mean 123 temperature ( $T m) . T x$ is the sum of $T m$ with the rise of the amplitudes, and $T n$ is the $T m$ minus the 124 amplitudes. The occurring times of the maximum/minimum temperature for both of the two125 harmonic synthesized annual and daily cycles are also calculated $\left(\Phi_{x_{-} a}, \Phi_{n_{-} a}, \Phi_{x_{-} d}, \Phi_{n_{-} d}\right)$. The 126 occurring times are associated with the two phases. Note that the annual maximum $/ \mathrm{minimum}$ 127 temperature and ATR are calculated based on the daily mean temperature to obtain the occurring 128 time change, which is different from traditional definitions where calculations are based on the monthly mean temperature. The differences in annual and daily cycles were compared between urban and rural stations. The long term changes of annual and daily cycles were quantified by linear regression, and the significance of the linear trend was tested by ANOVA F test. 


\section{Results}

133

134

135

136

137

138

139

140

141

142

143

144

145

146

147

148

149

150

151

152

153

154

155

156

157

3.1 Comparison of the four harmonics and two-harmonic synthesized annual/daily cycles

The results from 2014 are selected to compare the differences in the four harmonics and the two-harmonic synthesized annual/daily cycle between the four stations (Fig. 3). The urban stations were found to have larger phase and smaller amplitude for these four harmonics, with a very slight difference in annual and semi-annual harmonics (Fig. 3a, c) and the most evident difference in the daily harmonic (Fig. 3b). The annual amplitude measured at the urban stations was $7.45^{\circ} \mathrm{C}$ at $\mathrm{HKO}$ and $7.43^{\circ} \mathrm{C}$ at $\mathrm{KP}$, and at the rural stations $7.76^{\circ} \mathrm{C}$ at TKL and $7.54^{\circ} \mathrm{C}$ at $\mathrm{TYW}$. The annual phase (days) was 209.5 at HKO; 208.38 at KP; 206.52 at TKL and 204.95 at TYW. The daily amplitudes in the urban stations (HKO $1.30^{\circ} \mathrm{C}$ and $\mathrm{KP} 1.59^{\circ} \mathrm{C}$ ) are much smaller than those in the rural stations (TKL $2.77^{\circ} \mathrm{C}$ and TYW $2.88^{\circ} \mathrm{C}$ ), while the daily phase is much larger in HKO (15.20 hours) than the real rural station TYW (13.52 hours). The daily phase was 14.25 hours at both KP and TKL (Fig. 3b). Similar to the daily harmonic, the semi-daily harmonic showed a significant difference between the four stations, with a much smaller semi-daily amplitude and larger semi-daily phase in the urban stations (Fig. 3d).

There are subtle differences in both the annual and semi-annual harmonics between the four stations, while the two-harmonic synthesized annual variations of the air temperature are similar and the urban stations have the higher mean temperature, which suggests that an urban heat island effect existed throughout the whole year (Fig. 3e). However, the two-harmonic synthesized daily cycle variations are entirely different between the four stations. In the urban stations, the daily maximum temperature is cooler, while the daily minimum temperature is much warmer than in the rural stations, resulting in a much smaller DTR. The phase of the daily and semi-daily harmonics demonstrates that the daily maximum and daily minimum temperature appeared much later in the HKO stations (Fig. 3f).

Similar results are revealed when the average values from 2000 to 2014 are considered (Table 1; Table 2). 
Hong Kong has experienced a significant warming in air temperature since the late 19th century. Analysis of the mean temperature data from the Hong Kong Observatory showed that there was an average rise of $0.0118^{\circ} \mathrm{C}$ per year from 1885 to 2014 , which is smaller than the longterm warming trend in eastern China for a similar period (Qian 2016), as the observed warming trend is much larger in the higher latitudes (Wang and Dillon 2014). The warming rate being slightly higher than the adjusted warming trend after de-urbanization in eastern China (Qian 2016) and the globally averaged $0.85^{\circ} \mathrm{C}$ per-century warming for a similar period (IPCC 2013) suggest that global warming and the local urbanization effect may both contribute to the urban warming of Hong Kong. From the 1880 s to the 1960 s, the warming trend was slight, while dramatic warming occurred between the 1980s and the 2000s. The temperature showed decreasing trends in two periods, from the 1960 s to the 1980 s and from the 2000s to the present. The other urban station, KP, only presents the same decadal change of mean temperature from the 1990s due to data availability, while the temperature was consistently $0.3^{\circ} \mathrm{C}$ cooler than at $\mathrm{HKO}$. The two rural stations show different characteristics of mean temperature variation, and both were more than

$1731{ }^{\circ} \mathrm{C}$ cooler than the HKO urban stations (Table 1, Fig. 4). We compared the annual mean temperature data for HKO and TKL for the same period of 1989 to 2014 and found the warming rate experienced by $\mathrm{HKO}\left(0.0082^{\circ} \mathrm{C}\right.$ per year $)$ to be twice that of TKL $\left(0.0045^{\circ} \mathrm{C}\right.$ per year $)$. Thus, the local urban effect could be estimated to contribute $50 \%$ of the warming of the air temperature in the urban area of Hong Kong from 1989 to 2014. As the HKO station trend reversed to show a decrease after 2000, the TYW station also showed a cooling trend from 2000-2014.

For the annual harmonic, two main phenomena can be identified. First, all four stations 181 show negligible differences in annual and semi-annual harmonics. The differences between the 182 four stations are too small to be distinguished from the figures (Fig. 5). The Pearson correlation 183 coefficients of the four stations are significantly positive. For example, the four stations appear to 184 have experienced similar variations for the annual phase through the simultaneous observations 185 (Table 4). Second, no obvious trend in the changes of the amplitudes in the urban station HKO is 186 observed over the past 130 years, either in annual amplitude $\left(-0.0018^{\circ} \mathrm{C} /\right.$ year, $\mathrm{P}$ value 0.0796$)$ or 
187 semi-annual amplitude $(0.0006 \mathrm{C} / \mathrm{year}, \mathrm{P}$ value 0.4918$)$. The phases show decreasing trends 188 (annual phase: -0.0244 days/year, P value 0.0095, semi-annual phase: -0.0672 days/year, $\mathrm{P}$ value $1890.0325)$.

The changes in the daily amplitudes and phases show totally different characteristics from those in the annual amplitudes and phases. For daily and semi-daily harmonics, significant discrepancies are found between the urban and rural stations. Taking the daily phase as an example, the calculated correlation coefficients between the four stations are all extremely small, and negative values even occur. The largest positive correlation appears between the two rural stations and is significant at a 0.05 level.

The daily amplitude in the urban stations is much smaller than in rural stations, while the phase is much larger. Over the past 130 years, the amplitude change in HKO data can be divided into three periods. Before the $1960 \mathrm{~s}$, the amplitude showed a slightly increasing trend. From the 1960 s to the 1990 s, the trend began to dramatically decrease. After the 2000s, the amplitude leveled off. Due to the lack of data, the long-term change in amplitude of the rural stations could not be discovered. However, the amplitude and the decadal change appear to be approximately similar in the two rural stations.

In addition to the amplitude change, the difference in the changes in the daily phase between urban and rural stations is remarkable. The daily phase in the urban areas is more than one hour later than in the rural areas. What is striking is the clear growth trend in the time lag between the daily maximum air temperature and solar radiation, which amounts to a delay of over 1.5 hours during the past 130 years ( 0.0136 hours per year, significant at 0.01 level). Such a delay of phase lag has not been previously reported. No clear trend in the change in the phase of the daily air temperature cycle in other rural stations can be identified. The delay of the phase was unique, only occurring in urban areas. Interestingly, the daily phase at the rural station TYW in the 2000s is close to those taken at HKO in the late 1890s, when Hong Kong was just a village. characteristics to the daily harmonic except for the semi-daily phase. First, the difference in the semi-daily phase between urban and rural is much smaller than that of the daily phase. The semi- 
215 daily phase of HKO shows a continuous trend of delay over the past 130 years, which is also 216 different from that of the daily phase.

2173.4 Changes in annual and daily maximum/minimum temperatures

The urban stations have a higher mean temperature and slightly smaller amplitude and exhibit higher annual maximum and minimum temperatures than the rural stations (Table 2; Fig. 7). The difference between urban and rural stations is larger in terms of minimum temperature. Thus, the ATR is slightly smaller in the urban stations. However, the urban-rural difference in the daily pattern is totally different from the annual pattern. The urban daily maximum temperature is cooler than the rural daily maximum, while the urban daily minimum temperature is much warmer. The DTR is dramatically smaller in the urban area. Taking 2000-2014 average data of HKO and TYW as an example, their difference in annual maximum temperature is $1{ }^{\circ} \mathrm{C}$, while their difference in annual minimum temperature is $1.8^{\circ} \mathrm{C}$. The ATR in $\mathrm{HKO}$ is $0.79^{\circ} \mathrm{C}$ smaller than that in TYW. The daily maximum temperature in $\mathrm{HKO}$ is $0.88^{\circ} \mathrm{C}$ cooler than TYW, while the daily minimum temperature is $2.39^{\circ} \mathrm{C}$ warmer. Thus, the DTR in HKO station is less than half of that in TYW $\left(2.92^{\circ} \mathrm{C}\right.$ to $\left.6.19^{\circ} \mathrm{C}\right)$ (Table 2$)$.

For the last 130 years, the warming trends of the annual maximum and annual minimum temperatures are comparable, at $0.0105^{\circ} \mathrm{C}$ per year and $0.0136^{\circ} \mathrm{C}$ per year. Both are significant at the 0.01 level and very similar to the trend of the mean temperature. Thus, ATR showed a very slightly decreasing trend $\left(-0.0031^{\circ} \mathrm{C}\right.$ per year, $\mathrm{P}$ value 0.1391$)$. Fig. 7 illustrates that the annual maximum and minimum temperatures have not shown any obvious break or abruption over the time period. The linear trends of the daily maximum and minimum temperatures for the whole period between 1885 and 2014 are comparable $\left(0.0123^{\circ} \mathrm{C}\right.$ and $0.0105^{\circ} \mathrm{C}$ per year), and the DTR changed increased very subtly over 130 years $\left(0.0018^{\circ} \mathrm{C}\right.$ per year). However, the daily maximum and minimum temperatures also showed discontinuities (Fig. 7), as both daily amplitudes experienced discontinuous variations (Fig. 6). The changes of daily maximum and minimum temperatures and DTR must be examined in three different periods (Table 6). From 1885 to 1959, the daily maximum temperature increased much faster than daily minimum temperature, resulting in the increasing DTR. From 1960 to 1999, the daily maximum temperature started to show a decreasing trend, while the daily minimum temperature showed an even larger warming trend 
compared to the former period, producing a significant decreasing trend of DTR during this period.

245 After 2000, abruptions then occurred, and the daily maximum and minimum temperatures and

246 DTR all reversed from the former period. The daily maximum temperature increased while the

247 daily minimum temperature decreased, generated the increasing DTR.

3.5 Variations in the occurring times of maximum and minimum temperatures

Our analysis of the four harmonics demonstrates that the diversity in the annual phase is much smaller than in the daily phase between the four stations. Closely related to the phases, the differences in the occurring times of annual maximum and minimum temperatures are smaller than in the occurring times of the daily maximum and minimum temperatures between different stations (Fig. 8; Table 2).

In the HKO stations, both the annual phase and the semi-annual phase showed decreasing trends over the 130-year period. However, the annual warmest time and coolest time moved in the opposite direction. The annual warmest time was delayed (0.0466 days per year, $P$ value 0.1257 , while the annual coolest time appeared earlier (-0.0575 days per year, P value 0.0002$)$. In contrast, both the daily phase and the semi-daily phase showed increasing trends over the 130 years at HKO. The daily warmest and coolest times were both delayed, as the two phases show. The daily coolest time delayed with a trend of 0.0125 hour per year (P value 0 ), which is larger than the 0.0107 (P value 0 ) hour per year for the daily warmest time. The main difference between the daily warmest and coolest times appeared after 2000, when the daily warmest time reversed to show a decreasing trend and the daily coolest time continued to show a delaying trend (Fig. 8).

\section{Discussion and conclusions}

Different temperature cycles are associated with different spatial scales (Mitchell 1976). Our results show that the difference in annual cycles between urban and rural stations is much smaller than that in daily cycles, suggesting that the urban area has a greater effect on daily cycles than on annual cycles. Studies have demonstrated that the factors affecting the annual cycle range from regional to global; these include latitude, altitude, distance to the ocean, greenhouse-gas forcing and atmospheric circulation (Cornes et al. 2017; McKinnon et al. 2013; Prescott and 
variations in the annual cycles of the four stations in Hong Kong indicate that urban areas have very little impact on the annual cycle. The change in annual cycles may be a large-scale phenomenon. The decreased annual amplitudes and ATR suggest a larger warming trend in winter than in summer, which has been revealed by observations (Balling Jr et al. 1998; Luterbacher et al. 2004; Stine et al. 2009), reanalysis (Cornes et al. 2017), and CMIP5 models (Qian and Zhang 2015). Qian and Zhang (2015) analyzed the observation and CMIP5 model outputs to study the contributions of different nature and anthropogenic forcing to the observed decreasing annual amplitude and suggested that the prominent signal on changes in the annual temperature cycle only from the greenhouse gas effect and land use change seems to contribute little. As the major factor accompanying the urbanization effect on urban climate is the land use/cover change, the observed similar annual patterns of air temperature between urban and rural stations in this study also suggest that the land use/cover change contribute little to the annual cycle. The long-term change in annual phases in HKO data also confirmed findings in the analysis of annual phase or change of seasons that revealed a shift in the annual phase (Stine et al. 2009) and the earlier onset of seasons (Cassou and Cattiaux 2016; Cayan et al. 2001), which are also consistent with the annual coolest time in HKO occurring significantly earlier. However, the delayed annual warmest time has not been previously reported. The exact mechanism of the annual coolest and warmest times requires further study.

Unlike annual cycles, the difference in daily cycles between urban and rural stations is distinct, which implies that the daily cycle is more appropriate to indicate urban local climate change. In the urban area of Hong Kong, the daily maximum temperature is smaller, while the minimum temperature is much larger, so the DTR in the urban area is dramatically smaller. The daily phases or daily warmest and coolest times all occur much later in the urban area. The characteristics in amplitudes (DTR) and phases (or warmest and coolest time) can be mainly ascribed to thermal storage. The smaller daily amplitudes and DTR may be associated with increased thermal storage in the urban area. Yang et al. (2017) suggested that the thermal storage of the urban area is the main force behind the urban cool island clearly observed in Hong Kong. The larger thermal storage dampens the urban surface temperature, making it and the air temperature cooler in the daytime. This explanation is related to the phenomenon of the urban heat sink, where the city surface temperature is cooler than the surrounding area (Carnahan and Larson 1990; Giannaros et al. 2013). The strong night-time urban heat island may be due to the 
combination effect of urban thermal storage and anthropogenic heat. Another phenomenon of concern is that the daily and semi-daily phases and daily warmest and coolest times are all delayed. Kuo (1968) developed a radiative conductive atmospheric boundary layer model to study the thermal interaction between the atmosphere and the underlying ground, related to diurnal solar radiative heating. The results showed that the phase lag of the near surface potential temperature cycle is determined by the effective heat capacities of the atmosphere and the surface. Wang et al. (2017) developed a conceptual energy balance model to study the urban temperature cycle. The analytical solution suggested that the changes in amplitude and phase are independent from the mean temperature. The amplitude and phase are mainly determined by the effective thermal storage. Therefore, the increasing number of human-made structures in the urban area, such as buildings and roads, which have low reflectivity and high thermal capacity, have increased the thermal storage of the cities. A delayed daily phase and occurring time of the daily maximum and minimum temperatures can thus be expected.

However, the daily amplitudes (DTR) and phases (or warmest and coolest time) in HKO did not show consistent decreasing or delaying phenomena during the study period. The long-term daily amplitudes and DTR showed discontinuities over the past 130 years: they experienced an increasing trend before the 1960s, then decreased from the 1960s to the 1990s, then reversed again to show an increasing trend after 2000. The reversed trend of the DTR after the 1990s were also reported in China (Qian et al 2011; Wang et al 2012). The long-term observations were consistent with the long-term variation of the DTR reported for most areas of the world (Thorne et al. 2016a; Thorne et al. 2016b; Wild 2009). Although we found a significant delaying of the phases and timings of daily maximum and minimum temperatures, the phase delay mainly occurred before the 1910s and from the 1940s to the 1990s. There was a surprising phase advance phenomenon, i.e., a significant daily phase advance and daily warmest time, earlier in HKO, during the 1910s1940s and the 2000s. As far as we are aware, these phase delay and advance phenomena have not been previously reported or explained. We suggest that the thermal storage increase is the main influencing parameter for the observed phase delay phenomenon. However, the observed significant phase advance phenomenon suggests that changes in solar radiation and the effect of air pollution (through its effect on solar radiation) are significant, but their exact mechanisms are at present unknown. The phase delay and advance in the different periods coincide with the dimming and brightening in global solar radiation (Wild 2009), which suggests that the daily 
temperature cycle is also closely related to larger-scale climate factors. The understanding of the nonlinear multi-decadal variations in daily temperature cycles may help us identify any relationship between global warming and urban warming, and perhaps in particular the effect of global warming on urban warming. Such variations in daily cycles of HKO also suggested that, other than simple linear trends, the nonlinear approaches may be more accurate in describing the multi decadal variations (Qian 2016; Wu et al 2007).

\section{Acknowledgments}

341

342

343

344

This work was funded by a RGC CRF project (HKU9/CRF/12G) of the Government of the Hong Kong SAR, China and a grant awarded by the Key Laboratory of Eco Planning and Green Building, Tsinghua University, MOE, China. We thank two anonymous reviewers for their valuable comments and suggestions. We would also like to thank Mr. Shun Chi-ming, Director of Hong Kong Observatory, and Dr. LEE Tsz-cheung for their help.

\section{References}

Arnfield AJ (2003) Two decades of urban climate research: a review of turbulence, exchanges of energy and water, and the urban heat island International Journal of Climatology 23:1-26

Balling Jr RC, Michaels PJ, Knappenberger PC (1998) Analysis of winter and summer warming rates in gridded temperature time series Climate Research 9:175-181

Cao C, Lee X, Liu S, Schultz N, Xiao W, Zhang M, Zhao L (2016) Urban heat islands in China enhanced by haze pollution Nature Communications 7:12509 doi:10.1038/ncomms12509

Carnahan WH, Larson RC (1990) An analysis of an urban heat sink Remote Sensing of Environment 33:65-71

Cassou C, Cattiaux J (2016) Disruption of the European climate seasonal clock in a warming world Nature Climate Change 6:589-594

Cayan DR, Dettinger MD, Kammerdiener SA, Caprio JM, Peterson DH (2001) Changes in the onset of spring in the western United States Bulletin of the American Meteorological Society 82:399-415

Chan H, Kok M, Lee T (2012) Temperature trends in Hong Kong from a seasonal perspective Climate Research 55:53-63

Cornes RC, Jones P, Qian C (2017) Twentieth-century trends in the annual cycle of temperature across the northern hemisphere Journal of Climate, doi:10.1175/JCLI-D-16-0315.1 
Duren RM, Miller CE (2012) Measuring the carbon emissions of megacities Nature Climate Change 2:560-562

Easterling DR et al. (1997) Maximum and minimum temperature trends for the globe Science 277:364-367

Gallo KP, Easterling DR, Peterson TC (1996) The influence of land use/land cover on climatological values of the diurnal temperature range Journal of Climate 9:2941-2944

Giannaros TM, Melas D, Daglis IA, Keramitsoglou I, Kourtidis K (2013) Numerical study of the urban heat island over Athens (Greece) with the WRF model Atmospheric Environment 73:103-111

IPCC (2013) Climate Change 2013: The Physical Science Basis. Contribution of Working Group I to the Fifth Assessment Report of the Intergovernmental Panel on Climate Change. Cambridge University Press, Cambridge, United Kingdom and New York, NY, USA. doi:10.1017/CBO9781107415324

Jones PD, Groisman PY, Coughlan M, Plummer N, Wang WC, Karl TR (1990) Assessment of urbanization effects in time series of surface air temperature over land Nature 347:169-172

Kuo HL (1968) The thermal interaction between the atmosphere and the earth and propagation of diurnal temperature waves Journal of the Atmospheric Sciences 25:682-717

Li L, Chan PW, Wang D, Tan M (2015) Rapid urbanization effect on local climate: intercomparison of climate trends in Shenzhen and Hong Kong, 1968-2013 Climate Research 63:145-155

Luterbacher J, Dietrich D, Xoplaki E, Grosjean M, Wanner H (2004) European seasonal and annual temperature variability, trends, and extremes since 1500 Science 303:1499-1503

McCarthy MP, Best MJ, Betts RA (2010) Climate change in cities due to global warming and urban effects Geophysical Research Letters 37, L09705, doi:10.1029/2010GL042845

McKinnon KA, Stine AR, Huybers P (2013) The spatial structure of the annual cycle in surface temperature: Amplitude, phase, and Lagrangian history Journal of Climate 26:7852-7862

Mitchell JM (1976) An overview of climatic variability and its causal mechanisms Quaternary Research 6:481-493

Oke TR (1987) Boundary layer climates. 2nd. Routledge

Prescott JA, Collins JA (1951) The lag of temperature behind solar radiation Quarterly Journal of the Royal Meteorological Society 77:121-126

Qian C. (2016) Disentangling the urbanization effect, multi-decadal variability, and secular trend in temperature in eastern China during 1909-2010 Atmospheric Science Letters 17:177182 
Qian C, Fu C, Wu Z (2011) Changes in the amplitude of the temperature annual cycle in China and their implication for climate change research Journal of Climate 24:5292-302

Qian, C, Zhang X. (2015) Human influences on changes in the temperature seasonality in mid-to high-latitude land areas Journal of Climate 28:5908-5921

Siu LW, Hart MA (2013) Quantifying urban heat island intensity in Hong Kong SAR, China Environmental monitoring and assessment 185:4383-4398

Stine AR, Huybers P (2012) Changes in the seasonal cycle of temperature and atmospheric circulation Journal of Climate 25:7362-7380

Stine AR, Huybers P, Fung IY (2009) Changes in the phase of the annual cycle of surface temperature Nature 457:435-440

Thorne $\mathrm{P}$ et al. (2016a) Reassessing changes in diurnal temperature range: Intercomparison and evaluation of existing global data set estimates Journal of Geophysical Research: Atmospheres 121:5138-5158

Thorne P et al. (2016b) Reassessing changes in diurnal temperature range: A new data set and characterization of data biases Journal of Geophysical Research: Atmospheres 121:51155137

Vinnikov KY, Robock A, Basist A (2002) Diurnal and seasonal cycles of trends of surface air temperature Journal of Geophysical Research: Atmospheres 107

Wang G, Dillon ME (2014) Recent geographic convergence in diurnal and annual temperature cycling flattens global thermal profiles Nature Climate Change 4:988-992

Wang K, Ye H, Chen F, Xiong Y, Wang C (2012) Urbanization effect on the diurnal temperature range: different roles under solar dimming and brightening Journal of Climate 25:10221027

Wang K, Li Y, Wang Y, Yang X (2017) On the asymmetry of the urban daily air temperature cycle Journal of Geophysical Research: Atmospheres 122, doi:10.1002/2017JD026589.

Wild M (2009) Global dimming and brightening: a review Journal of Geophysical Research: Atmospheres 114

Wong MC, Mok HY, Lee TC (2011) Observed changes in extreme weather indices in Hong Kong International Journal of Climatology 31:2300-2311

Wu Z, Huang NE, Long SR, Peng CK (2007) On the trend, detrending, and variability of nonlinear and nonstationary time series Proceedings of the National Academy of Sciences 104: 14889-14894.

Yang X, Li Y, Luo Z, Chan PW (2017) The urban cool island phenomenon in a high-rise highdensity city and its mechanisms International Journal of Climatology 37: 890-904 
433 Fig. 1 Locations of four selected meteorological stations in Hong Kong (a) and illustration of the 434 urban development around HKO stations from 1920s (b) to 2017 (c). (Figure 1b courtesy of Mr.

435 Shun Chi-ming)

436 Fig. 2 Discrete Fourier transform of sample data: (a) energy spectrum showing four major 437 harmonics in observed hourly data (meteorological station KP in 2000); (b) comparison of annual 438 hourly observed data and sum of four major harmonics; (c) comparison of monthly observed mean 439 temperature in 2000, annual harmonic and sum of annual and semi-annual harmonics; and (d) 440 comparison of observed average hourly mean in 2000, daily harmonic of observed average hourly 441 mean in 2000 and sum of daily and semi-daily harmonics.

442 Fig. 3 Comparison of the four major harmonics: the annual harmonic (a), daily harmonic (b), semi443 annual harmonic (c), and semi-daily harmonic (d) of the four selected stations in 2014. (e) and (f) 444 are the two-harmonic synthesized annual cycle and two-harmonic synthesized daily cycle, 445 respectively, which are calculated from the sum of two harmonics with mean temperature. Dashed 446 lines in these two figures denote the mean temperatures of the four stations.

447 Fig. 4 Change in the mean temperature at stations in Hong Kong.

448 Fig. 5 Changes in the annual and semi-annual harmonics in Hong Kong: (a) annual amplitude; (b) 449 annual phase; (c) semi-annual amplitude; (d) semi-annual phase. JDN is Julian day number.

450 Fig. 6 Changes in the daily harmonic and semi-daily harmonic in Hong Kong: (a) daily amplitude; 451 (b) daily phase; (c) semi-daily amplitude; (d) semi-daily phase. LST is local solar time.

452 Fig. 7 Changes in the two-harmonic synthesized annual and daily temperature cycles in Hong 453 Kong: (a) annual maximum temperature; (b) daily maximum temperature; (c) annual minimum 454 temperature; (d) daily minimum temperature; (e) annual temperature range; (f) diurnal temperature 455 range.

456 Fig. 8 Changes in the occurring times of annual maximum (a), annual minimum (c), daily 457 maximum (b) and daily minimum (d) temperatures. JDN is Julian day number, LST is local solar time. 


\section{Table Captions}

460 Table $12000-2014$ averages of the mean temperature $\left({ }^{\circ} \mathrm{C}\right)$, amplitude $\left({ }^{\circ} \mathrm{C}\right)$ and phase (day or hour)

461 of the four harmonics.

462 Table 2 The 2000-2014 averages of annual and daily maximum, minimum temperatures and 463 temperature ranges $\left({ }^{\circ} \mathrm{C}\right)$ in the four stations, and their occurring times (Julian day number or local 464 solar time), all calculated from two-harmonic synthesized annual and daily cycles.

465 Table 3 Linear trend in measurements taken at four Hong Kong meteorological stations.

466 Table 4 Pearson correlation coefficients of annual phase between four stations.

467 Table 5 Pearson correlation coefficients of the daily phase between the four stations.

468 Table 6 Linear trends $\left({ }^{\circ} \mathrm{C}\right.$ per year) of the daily maximum temperature $\left(T x \_d\right)$, daily minimum 469 temperature $\left(T n \_d\right)$ and DTR for different periods in HKO. 


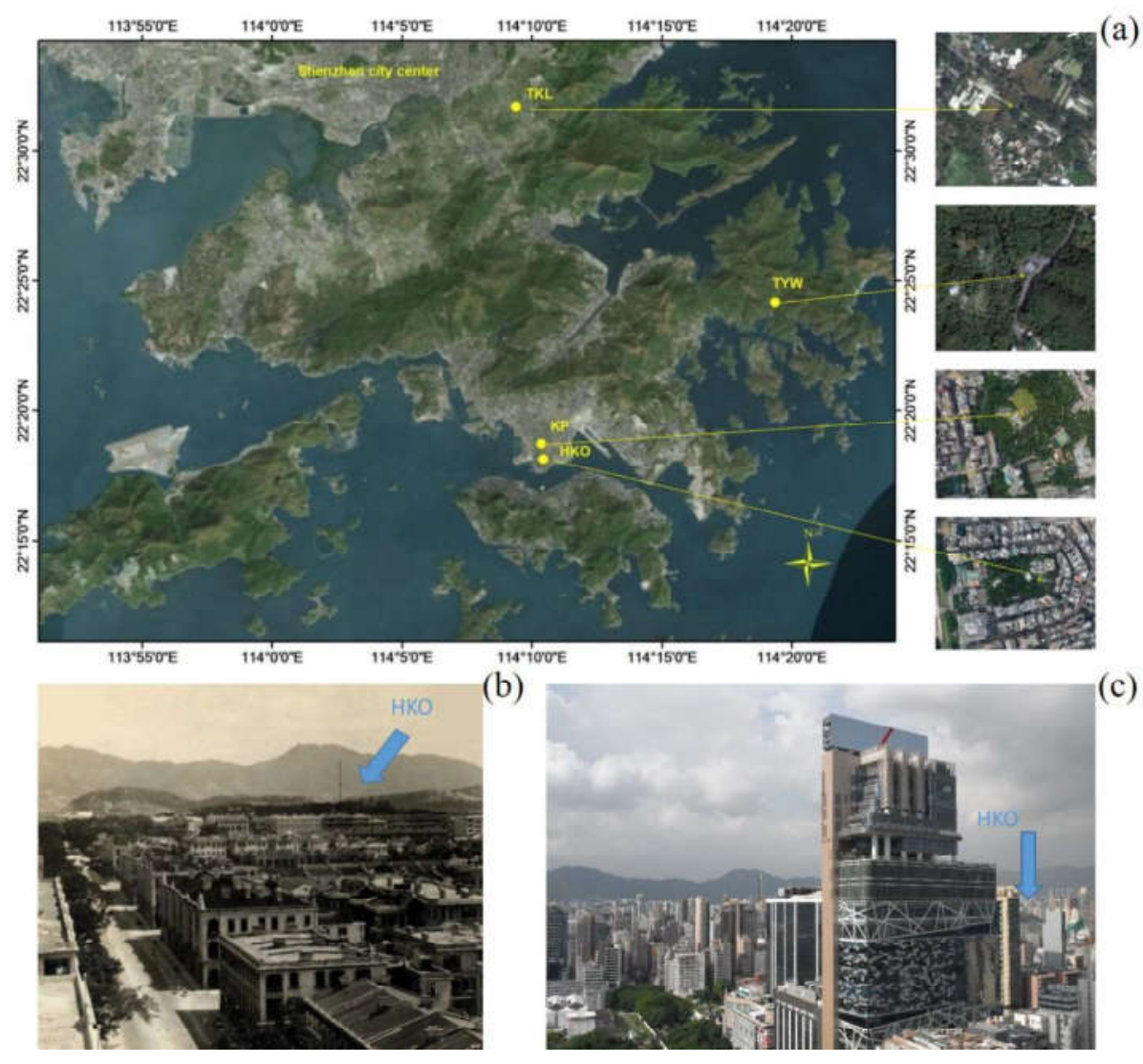

Fig. 1 Locations of four selected meteorological stations in Hong Kong (a) and illustration of the urban development around HKO stations from 1920s (b) to 2017 (c). (Figure 1b courtesy of Mr. Shun Chi-ming) 

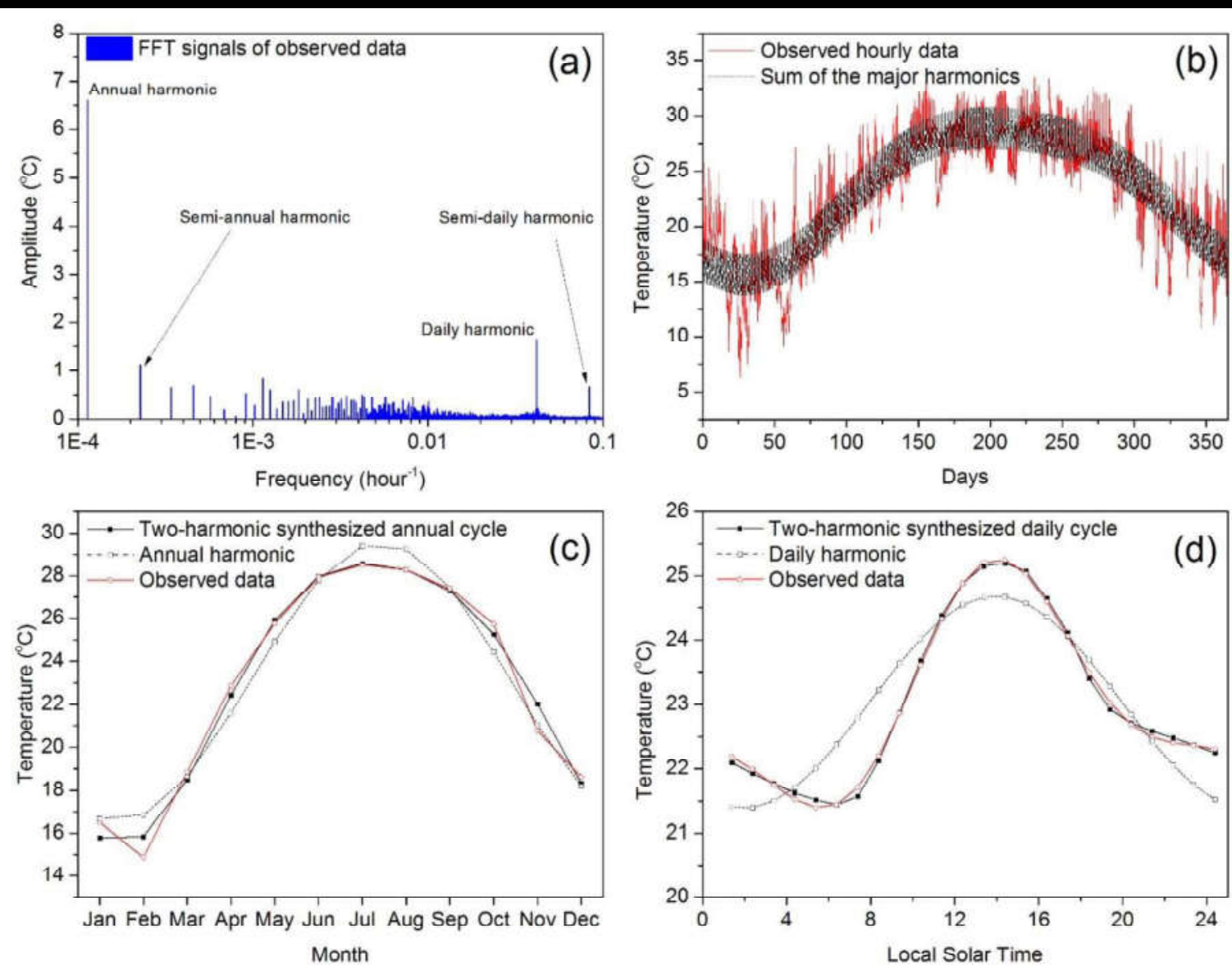

Fig. 2 Discrete Fourier transform of sample data: (a) energy spectrum showing four major harmonics in observed hourly data (meteorological station KP in 2000); (b) comparison of annual hourly observed data and sum of four major harmonics; (c) comparison of monthly observed mean temperature in 2000, annual harmonic and sum of annual and semi-annual harmonics; and (d) comparison of observed average hourly mean in 2000, daily harmonic of observed average hourly mean in 2000 and sum of daily and semi-daily harmonics. 

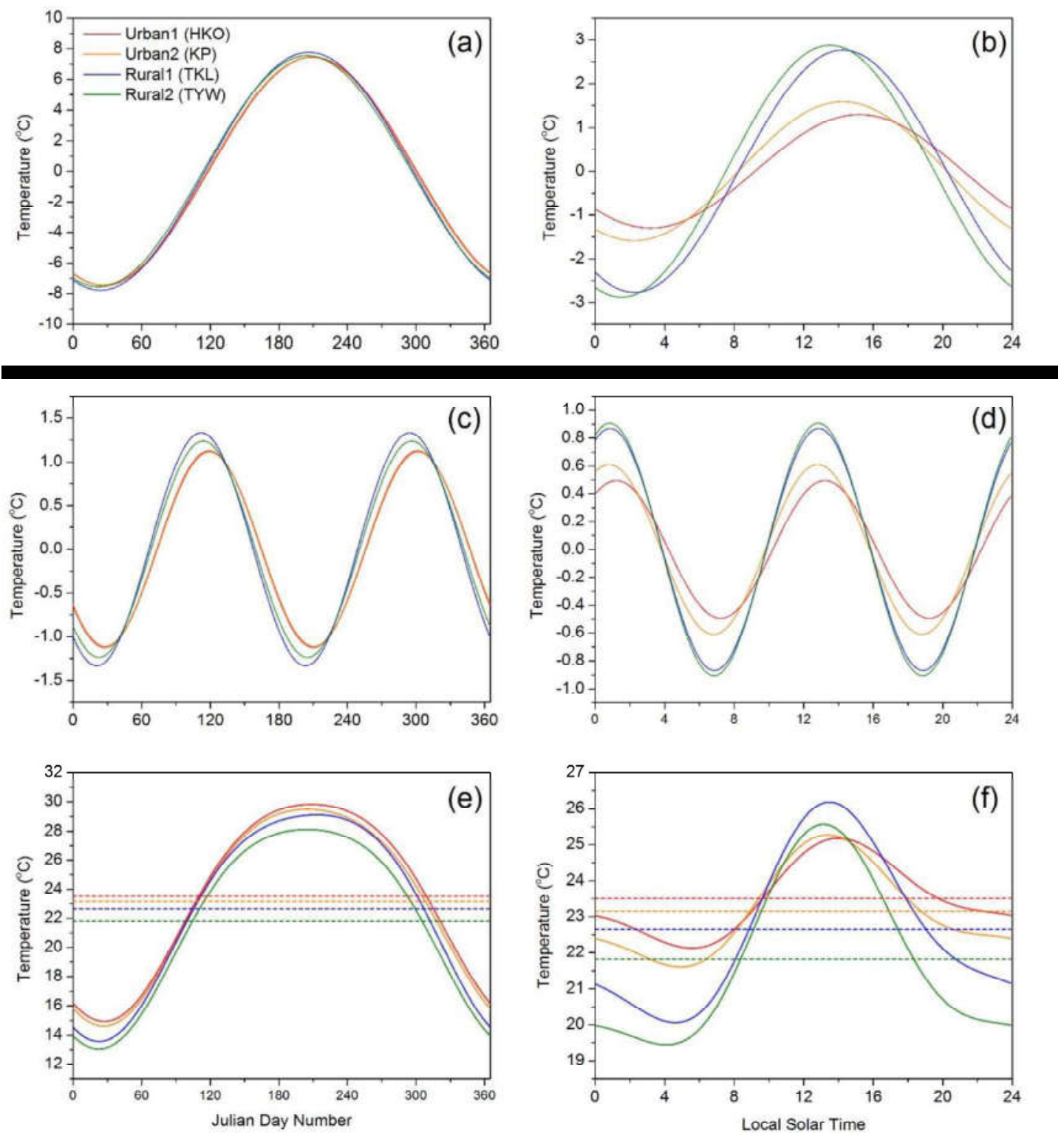

Fig. 3 Comparison of the four major harmonics: the annual harmonic (a), daily harmonic (b), semiannual harmonic (c), and semi-daily harmonic (d) of the four selected stations in 2014. (e) and (f) are the two-harmonic synthesized annual cycle and two-harmonic synthesized daily cycle, respectively, which are calculated from the sum of two harmonics with mean temperature. Dashed lines in these two figures denote the mean temperatures of the four stations. 


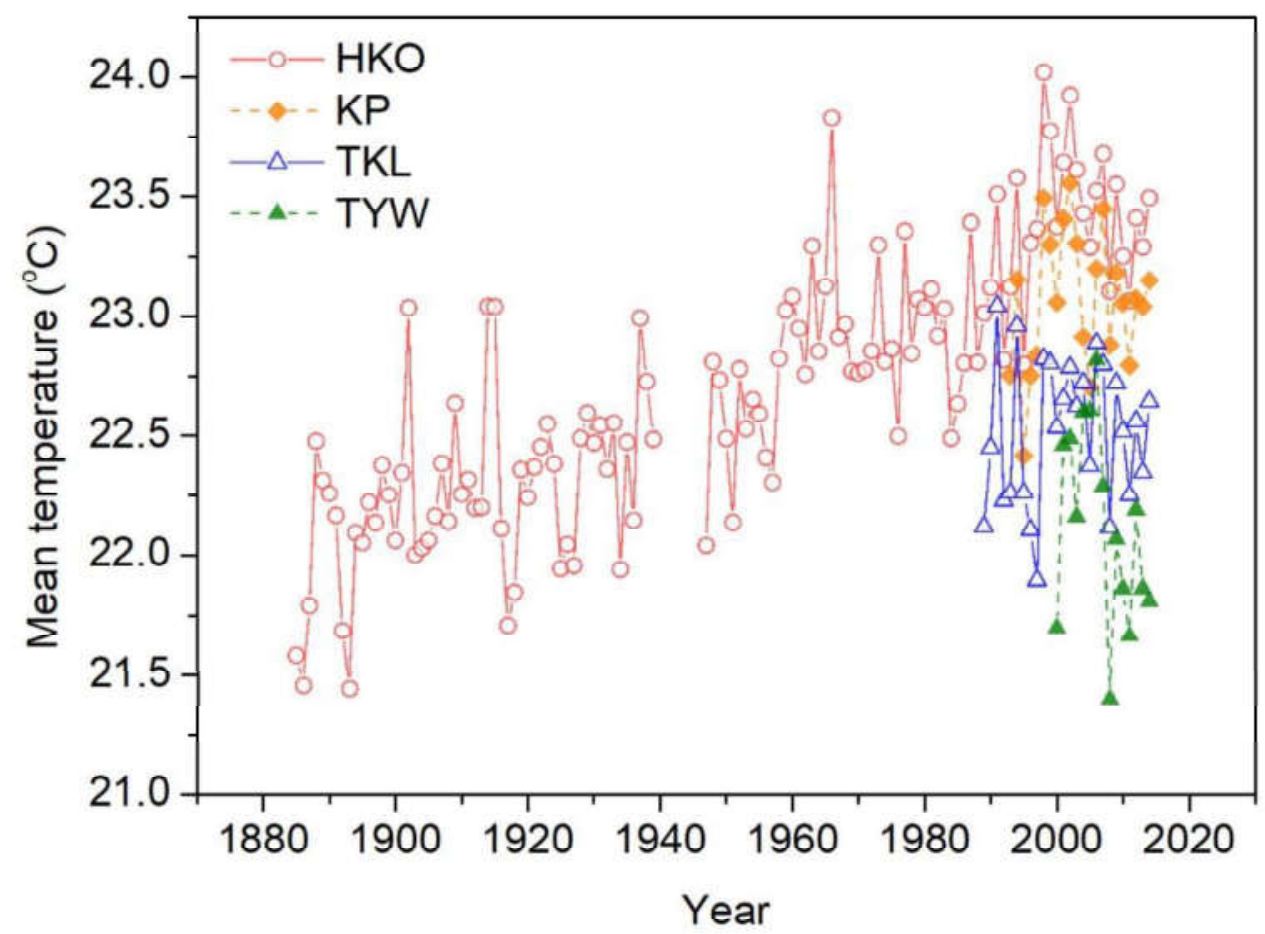

Fig. 4 Change in the mean temperature at stations in Hong Kong. 

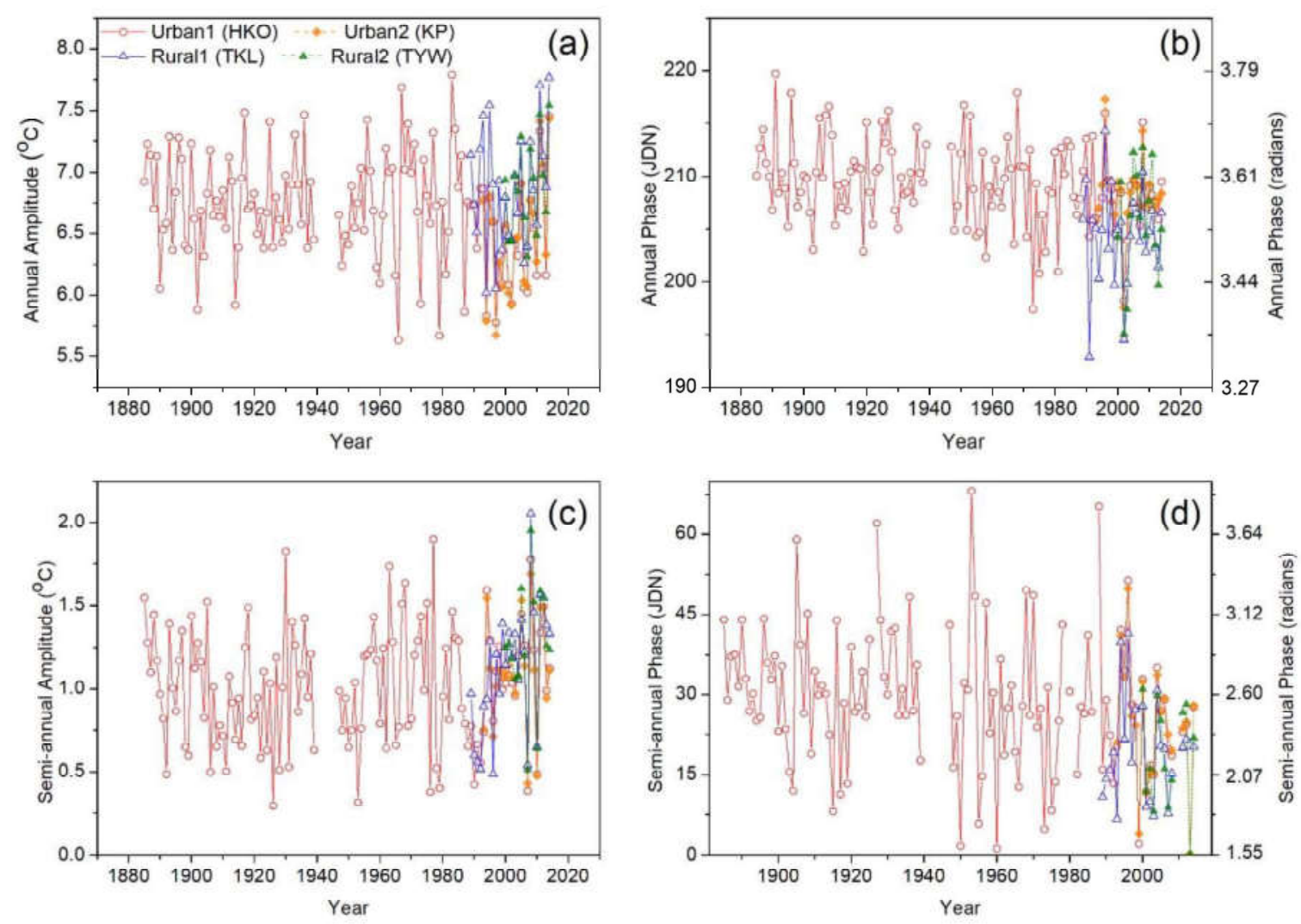

Fig. 5 Changes in the annual and semi-annual harmonics in Hong Kong: (a) annual amplitude; (b) annual phase; (c) semi-annual amplitude; (d) semi-annual phase. JDN is Julian day number. 

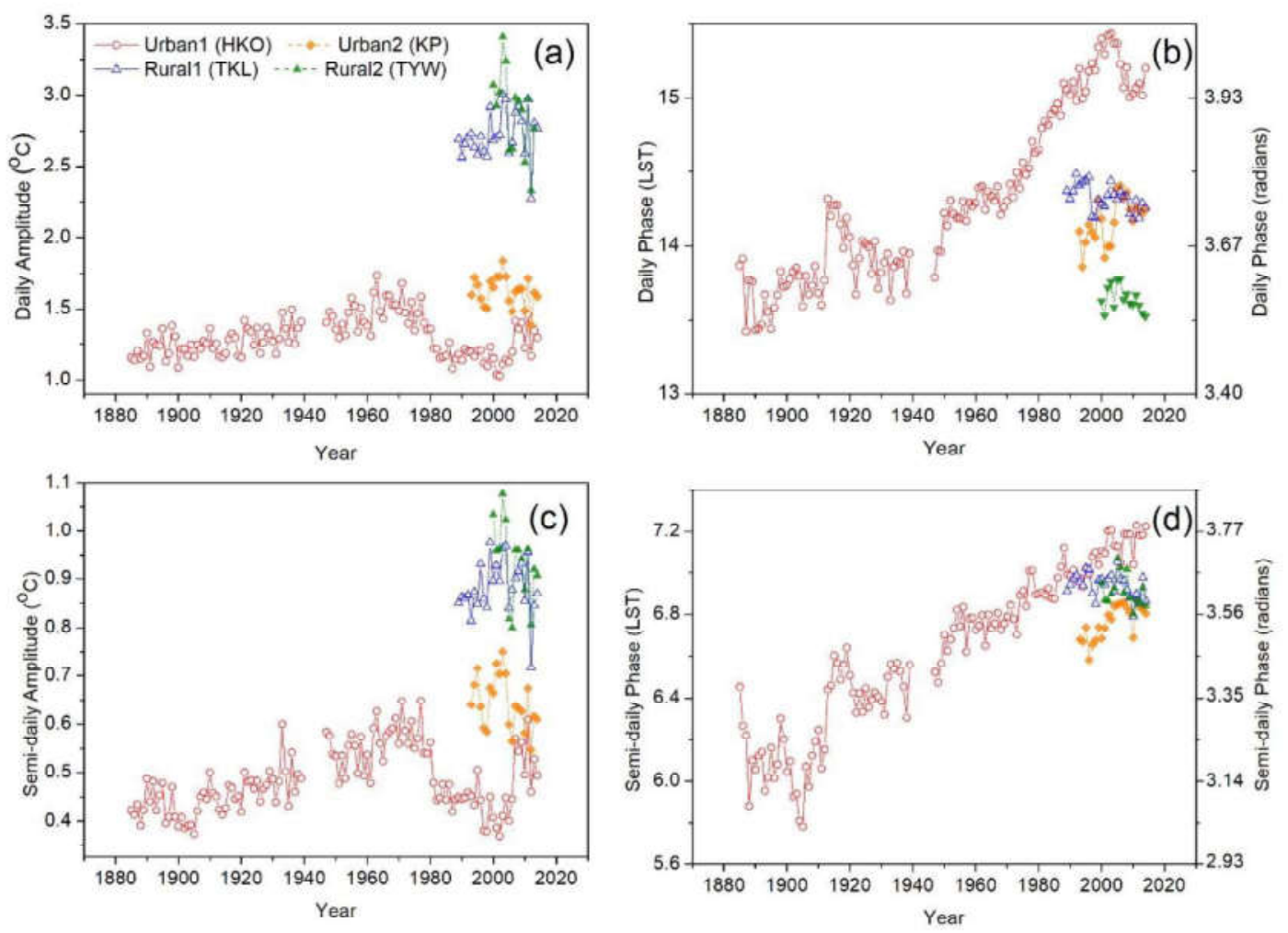

Fig. 6 Changes in the daily harmonic and semi-daily harmonic in Hong Kong: (a) daily amplitude; (b) daily phase; (c) semi-daily amplitude; (d) semi-daily phase. LST is local solar time. 

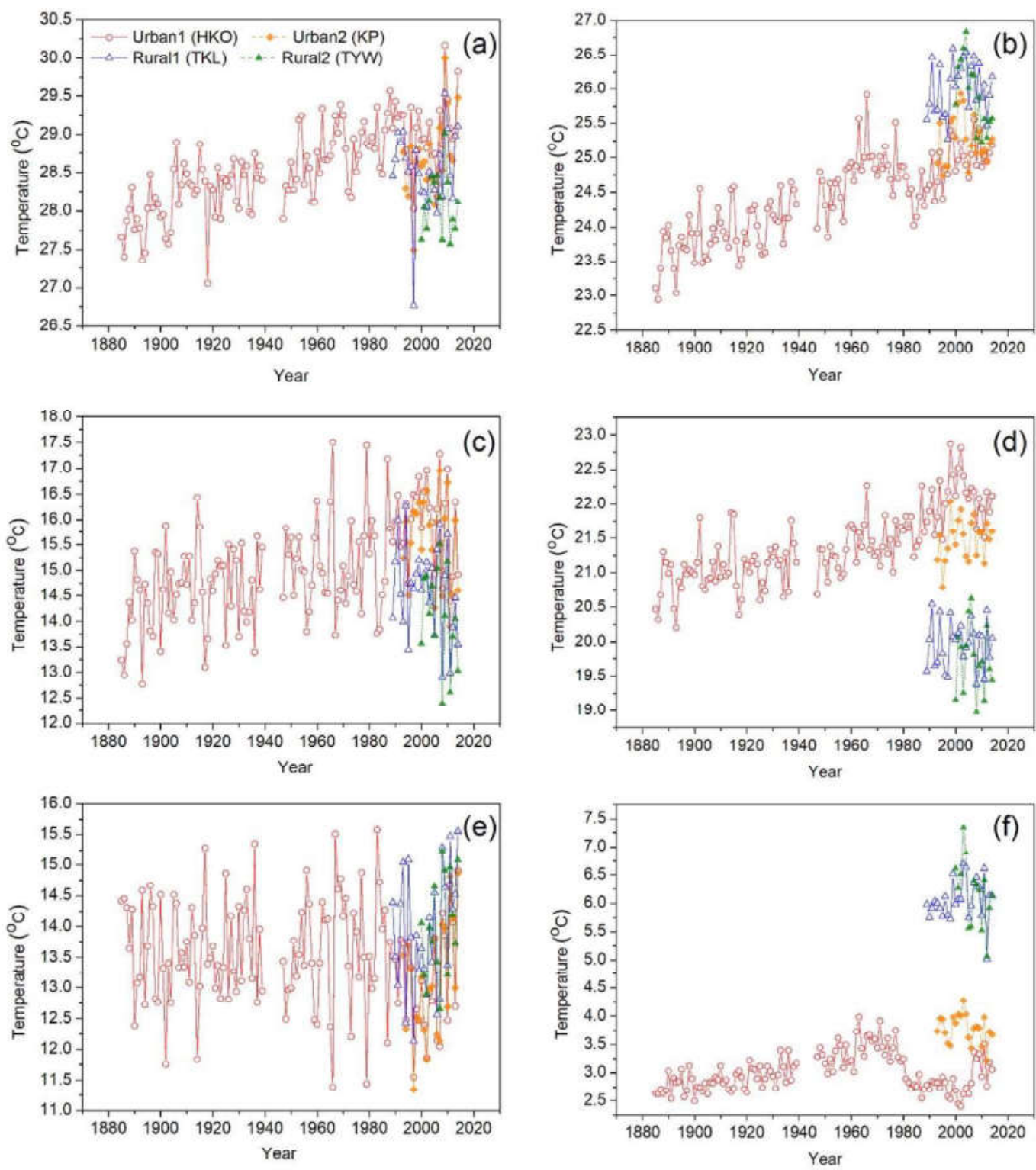

Fig. 7 Changes in the two-harmonic synthesized annual and daily temperature cycles in Hong Kong: (a) annual maximum temperature; (b) daily maximum temperature; (c) annual minimum temperature; (d) daily minimum temperature; (e) annual temperature range; (f) diurnal temperature range. 

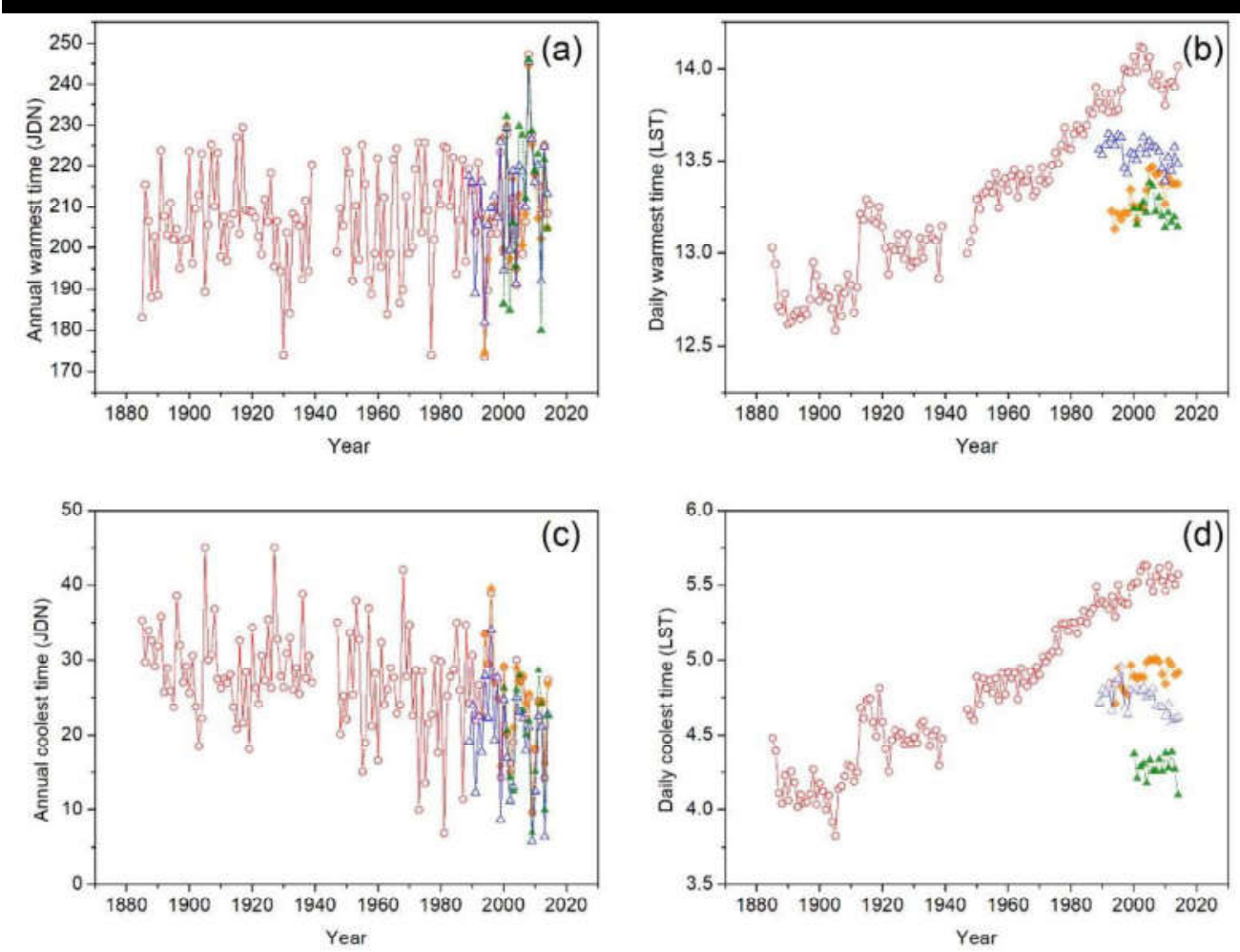

Fig. 8 Changes in the occurring times of annual maximum (a), annual minimum (c), daily maximum (b) and daily minimum (d) temperatures. JDN is Julian day number, LST is local solar time. 
Table $12000-2014$ averages of the mean temperature $\left({ }^{\circ} \mathrm{C}\right)$, amplitude $\left({ }^{\circ} \mathrm{C}\right)$ and phase (day or hour) of the four harmonics.

\begin{tabular}{|c|c|c|c|c|c|}
\hline \multicolumn{2}{|c|}{ Parameters } & \multirow{2}{*}{$\begin{array}{c}\mathrm{HKO} \\
23.44 \pm 0.23\end{array}$} & \multirow{2}{*}{$\begin{array}{c}\mathrm{KP} \\
23.12 \pm 0.24\end{array}$} & \multirow{2}{*}{$\begin{array}{c}\text { TKL } \\
22.57 \pm 0.22\end{array}$} & \multirow{2}{*}{$\begin{array}{c}\text { TYW } \\
22.13 \pm 0.41\end{array}$} \\
\hline Mean & $\mathrm{T}_{\mathrm{m}}$ & & & & \\
\hline & $\Delta \tilde{T}_{a 1}$ & $6.52 \pm 0.49$ & $6.56 \pm 0.48$ & $6.89 \pm 0.46$ & $6.87 \pm 0.38$ \\
\hline \multicolumn{6}{|l|}{ Annual } \\
\hline & $\Phi_{a 1}$ & $207.66 \pm 3.62$ & $207.84 \pm 3.41$ & $204.18 \pm 3.73$ & $205.70 \pm 5.34$ \\
\hline \multirow{2}{*}{$\begin{array}{l}\text { Semi- } \\
\text { annual }\end{array}$} & $\Delta \widetilde{T}_{a 2}$ & $1.12 \pm 0.35$ & $1.12 \pm 0.35$ & $1.28 \pm 0.36$ & $1.26 \pm 0.37$ \\
\hline & $\Phi_{a 2}$ & $23.44 \pm 7.25$ & $21.97 \pm 9.40$ & $17.73 \pm 7.82$ & $18.95 \pm 9.85$ \\
\hline & $\Delta \tilde{T}_{d 1}$ & $1.23 \pm 0.14$ & $1.63 \pm 0.12$ & $2.76 \pm 0.19$ & $2.88 \pm 0.28$ \\
\hline \multicolumn{6}{|l|}{ Daily } \\
\hline & $\Phi_{d 1}$ & $15.21 \pm 0.16$ & $14.21 \pm 0.14$ & $14.30 \pm 0.07$ & $13.64 \pm 0.08$ \\
\hline & $\Delta \widetilde{T}_{d 2}$ & $0.48 \pm 0.07$ & $0.64 \pm 0.06$ & $0.89 \pm 0.06$ & $0.93 \pm 0.08$ \\
\hline \multicolumn{6}{|c|}{ Semi-daily } \\
\hline & $\Phi_{d 2}$ & $7.16 \pm 0.06$ & $6.80 \pm 0.06$ & $6.93 \pm 0.06$ & $6.91 \pm 0.07$ \\
\hline
\end{tabular}


Table 2 The 2000-2014 averages of annual and daily maximum, minimum temperatures and temperature ranges $\left({ }^{\circ} \mathrm{C}\right)$ in the four stations, and their occurring times (Julian day number or local solar time), all calculated from two-harmonic synthesized annual and daily cycles.

\begin{tabular}{|c|c|c|c|c|c|}
\hline \multicolumn{2}{|c|}{ Parameters } & \multirow{2}{*}{$\begin{array}{c}\text { HKO } \\
29.09 \pm 0.45\end{array}$} & \multirow{2}{*}{$\begin{array}{c}\mathrm{KP} \\
28.80 \pm 0.52\end{array}$} & \multirow{2}{*}{$\begin{array}{c}\text { TKL } \\
28.53 \pm 0.45\end{array}$} & \multirow{2}{*}{$\begin{array}{c}\text { TYW } \\
28.09 \pm 0.40\end{array}$} \\
\hline Annual & $T x \_a$ & & & & \\
\hline maximum & $\Phi_{x_{-} a}$ & $212.71 \pm 14.77$ & $212.53 \pm 14.02$ & $214.69 \pm 15.19$ & $213.14 \pm 19.62$ \\
\hline Annual & Tn_a & $15.89 \pm 0.92$ & $15.54 \pm 0.97$ & $14.50 \pm 0.93$ & $14.09 \pm 0.94$ \\
\hline minimum & $\Phi_{n_{-} a}$ & $22.31 \pm 5.96$ & $22.57 \pm 5.71$ & $17.73 \pm 6.45$ & $20.00 \pm 6.73$ \\
\hline \multicolumn{2}{|c|}{ ATR } & $13.20 \pm 0.99$ & $13.27 \pm 0.96$ & $14.03 \pm 0.97$ & $13.99 \pm 0.83$ \\
\hline Daily & $T x \_d$ & $25.04 \pm 0.23$ & $25.32 \pm 0.34$ & $26.12 \pm 0.31$ & $25.92 \pm 0.50$ \\
\hline maximum & $\Phi_{x_{-} d}$ & $13.97 \pm 0.09$ & $13.35 \pm 0.09$ & $13.52 \pm 0.06$ & $13.23 \pm 0.07$ \\
\hline Daily & $T n \_d$ & $22.12 \pm 0.32$ & $21.53 \pm 0.25$ & $19.99 \pm 0.30$ & $19.73 \pm 0.49$ \\
\hline minimum & $\Phi_{n_{-} d}$ & $5.55 \pm 0.06$ & $4.894 \pm 0.06$ & $4.72 \pm 0.08$ & $4.28 \pm 0.08$ \\
\hline \multicolumn{2}{|c|}{ DTR } & $2.92 \pm 0.35$ & $3.79 \pm 0.27$ & $6.12 \pm 0.43$ & $6.19 \pm 0.58$ \\
\hline
\end{tabular}


Table 3 Linear trend in measurements taken at four Hong Kong meteorological stations.

\begin{tabular}{|c|c|c|c|c|c|}
\hline \multirow{2}{*}{\multicolumn{2}{|c|}{ Parameters }} & \multirow[t]{2}{*}{$H K O$} & \multirow[t]{2}{*}{$K P$} & \multirow[t]{2}{*}{$T K L$} & \multirow[t]{2}{*}{$T Y W$} \\
\hline & & & & & \\
\hline & & $(1885-2014)$ & $(1993-2014)$ & $(1989-2014)$ & $(2000-2014)$ \\
\hline Meal & ${ }^{\circ} \mathrm{C}$ per year) & $0.0118 *$ & 0.0070 & 0.0045 & -0.0393 \\
\hline \multirow{2}{*}{$\begin{array}{l}\text { Annual } \\
\text { Phase }\end{array}$} & (days per year) & $-0.0244^{*}$ & -0.0175 & 0.0209 & 0.1369 \\
\hline & (rad. per year) & $-0.0004 *$ & -0.0003 & 0.0003 & 0.0024 \\
\hline \multicolumn{2}{|c|}{ Annual Amplitude $\left({ }^{\circ} \mathbf{C}\right.$ per } & -0.0018 & 0.0335 & 0.0122 & 0.0329 \\
\hline $\begin{array}{l}\text { Semi- } \\
\text { annual }\end{array}$ & (days per year) & -0.0672 & -0.6462 & -0.1044 & -0.2298 \\
\hline Phase & (rad. per year) & -0.0023 & -0.0222 & -0.0036 & -0.0079 \\
\hline \multicolumn{2}{|c|}{ Semi-annual Amplitude $\left({ }^{\circ} \mathbf{C}\right.$} & 0.0006 & 0.0054 & $0.0287^{*}$ & 0.0109 \\
\hline \multirow{2}{*}{$\begin{array}{l}\text { Daily } \\
\text { Phase }\end{array}$} & (hours per year) & $0.0136 *$ & $0.0132 *$ & $-0.0060 *$ & -0.0070 \\
\hline & (rad. per year) & $0.0036 *$ & $0.0035^{*}$ & $-0.0016^{*}$ & -0.0018 \\
\hline Daily A & $\begin{array}{l}\text { iplitude }\left({ }^{\circ} \mathrm{C} \text { per }\right. \\
\text { year) }\end{array}$ & 0.0003 & -0.0035 & 0.0044 & -0.031 \\
\hline $\begin{array}{l}\text { Semi- } \\
\text { daily }\end{array}$ & (hours per year) & $0.0093^{*}$ & $0.0092 *$ & -0.0029 & -0.0049 \\
\hline Phase & (rad. per year) & $0.0049^{*}$ & $0.0048 *$ & -0.0015 & -0.0026 \\
\hline Semi-da & $\begin{array}{l}\text { y Amplitude }\left({ }^{\circ} \mathrm{C}\right. \\
\text { er year) }\end{array}$ & $0.0005^{*}$ & -0.0031 & 0.0004 & -0.0086 \\
\hline
\end{tabular}

* Significant at the 0.01 level 
Table 4 Pearson correlation coefficients of annual phase between four stations.

\begin{tabular}{|c|c|c|c|c|}
\hline & HKO & KP & TKL & TYW \\
\hline HKO & 1 & $0.95^{*}$ & $0.85^{*}$ & $0.82^{*}$ \\
\hline KP & $0.95^{*}$ & 1 & $0.84^{*}$ & $0.72^{*}$ \\
\hline TKL & $0.85^{*}$ & $0.84^{*}$ & 1 & $0.92^{*}$ \\
\hline TYW & $0.82^{*}$ & $0.72^{*}$ & $0.92^{*}$ & 1 \\
\hline
\end{tabular}

*all significant at 0.01 level

Table 5 Pearson correlation coefficients of the daily phase between the four stations.

\begin{tabular}{|c|c|c|c|c|}
\hline & HKO & KP & TKL & TYW \\
\hline HKO & 1 & -0.24 & -0.01 & 0.41 \\
\hline KP & -0.24 & 1 & -0.22 & 0.26 \\
\hline TKL & -0.01 & -0.22 & 1 & $0.62^{*}$ \\
\hline TYW & 0.41 & 0.26 & $0.62^{*}$ & 1 \\
\hline
\end{tabular}

*significant at 0.05 level 
Table 6 Linear trends $\left({ }^{\circ} \mathrm{C}\right.$ per year) of the daily maximum temperature $\left(T x \_d\right)$, daily minimum temperature $\left(T n \_d\right)$ and DTR for different periods in HKO.

\begin{tabular}{cccc}
\hline & $T x_{-} d$ & $T n_{-} d$ & DTR \\
\hline $1885-1959$ & $\mathbf{0 . 0 1 4 0 *}^{*}$ & $\mathbf{0 . 0 0 5 2}^{*}$ & $\mathbf{0 . 0 0 8 7}^{*}$ \\
& & & \\
$1960-1999$ & -0.0089 & $\mathbf{0 . 0 1 8 7 ^ { * }}$ & $\mathbf{- 0 . 0 2 7 2 *}$ \\
& & & \\
$2000-2014$ & 0.0110 & -0.0423 & $\mathbf{0 . 0 5 3 3} *$ \\
& & & \\
$1885-2014$ & $\mathbf{0 . 0 1 2 3} *$ & $\mathbf{0 . 0 1 0 5} *$ & 0.0018 \\
\hline
\end{tabular}

* Significant at the 0.01 level 